Cell Research (1999), 9, 91-105

\title{
Spatial and temporal regulation of collagenases-3, -4 , and stromelysin -3 implicates distinct functions in apoptosis and tissue remodeling during frog metamorphosis
}

\author{
Damjanoviki Sashko ${ }^{1}$,Atsuko Ishizuya-okA ${ }^{2, *}$, Yun-bo $^{2}$ \\ $\mathrm{SHI}^{1, *}$ \\ 1 Laboratory of Molecular Embryology, Building 18T, Rm. 106, \\ National Institute of Child Health and Human Development, \\ National Institutes of Health, Bethesda, MD, 20892, USA \\ 2 Department of Histology and Neurobiology, Dokkyo Univer- \\ sity School of Medicine, Mibu, Tochigi 321-02, Japan
}

\begin{abstract}
Matrix metalloproteinases (MMPs) are a family of extracellular proteases capable of degrading various proteinaceous components of the extracellular matrix (ECM). They have been implicated to play important roles in a number of developmental and pathological processes, such as tumor metastasis and inflammation. Relatively few studies have been carried out to investigate the function of MMPs during postembryonic organ-development. Using Xenopus laevis development as a model system, we demonstrate here that three MMPs, stromelysin-3 (ST3), collagenases-3 (Col3), and Col4, have distinct spatial and temporal expression profiles during metamorphosis as the tadpole transforms into a frog. In situ hybridizations reveal a tight, but distinct, association of individual MMPs with tissue remodeling in the tail and intestine during metamorphosis. In particular, ST3 expression is strongly correlated with apoptosis in both organs as demonstrated by analyses of serial sections with in situ hybridization for ST3 mRNA and TUNEL (terminal deoxyribonucleotidyl transferase-mediated dUTP-biotin nick end labeling) for apoptosis, respectively. On the other
\end{abstract}

\footnotetext{
* Corresponding author: Yun-Bo Shi Laboratory of Molecular Embryology Building 18T,Rm 106 National Institute of Child Health and Human Development National Institutes of Health Bethesda, MD 20892, USA (301) 402-1004, (301) 402-1323(fax), shi@helix.nih.gov
} 
MMPs in Xenopus laevis development

hand, Col3 and Col4 are present in regions where extensive connective tissue remodeling take place. These results indicate that ST3 is likely to play a role in ECM-remodeling that facilitate apoptotic tissue remodeling or resorption while Col3 and Col4 appear to participate in connective tissue degradation during development.

Key words: Apoptosis, thyroid hormone, matrix metalloproteinase, extracellular matrix (ECM), amphibian.

\section{INTRODUCTION}

Cell signaling and migration are two of the crucial events common to all multicellular organisms, particularly vertebrates. As a single fertilized egg divides into numerous cells, it is in large part the extracellular matrix (ECM), which the cells themselves create, that provides the distinct environments for proper cell-cell interactions to guide the cells to specific developmental pathways[1]. Not only are important cytokines, morphogens, and growth factors forced to pass through ECM in order to reach their target cells to carry out their signaling function, but important cell-cell communications through molecules such as cadherins, are all controlled by the compositions of the local ECM environment. Furthermore, cell-ECM contacts can directly affect cell fate determination, e.g., apoptosis vs. proliferation and differentiation, attachment vs. migration[2]. Thus, it is easy to envision that establishing and maintaining a proper ECM environment plays critical roles in organogenesis and tissue remodeling during development.

ECM remodeling is to a large extent mediated by matrix metalloproteinases (MMPs), a family of $\mathrm{Zn}^{2+}$-dependent proteases that are capable of degrading proteinaceous components of the ECM[3-6]. About 20 different MMPs have been identified in vertebrates, including collagenases, gelatinases, stromelysins, and membrane-type MMPs, etc. MMPs are secreted as inactive proenzymes, with the exception of stromelysin-3 (ST3) and membrane-type MMPs[7],[8], that are activated intracellularly. The proenzymes are kept inactive due to the formation of a fourth coordination bond with the catalytic $\mathrm{Zn}^{2+}$ by a conserved cysteine residue in the propeptide[9]. The proenzymes can be activated in the ECM or on the cell surface through the proteolytic removal of the propeptide[10-13]. Different activated MMPs have distinct but overlapping substrate specificity and collectively they can degrade all proteinaceous components of the ECM[8],[14]. Thus, differential regulation of the levels of various MMPs may lead to distinct ECM remodeling events, thereby resulting in different biological consequences. In fact, MMP genes have been shown to be regulated differentially in different developmental and pathological processes, 
such as post-lactation involution of the mammary gland and cancer metastasis in mammals[15-17].

We are interested in the roles of different MMPs during development. We have chosen the South African toad Xenopus laevis as a model system. Xenopus laevis embryo develops externally and independent of maternal influence. Like other anurans, Xenopus laevis undergoes a biphasic developmental process, first forming a free living tadpole and subsequently metamorphosing into the adult form, which has a very different living habitat. An important advantage of this metamorphic process is its absolute dependence on thyroid hormone (TH)[18],[19]. TH has been shown to regulate amphibian metamorphosis organ-autonomously and in many cases, cell-autonomously by directly controlling the expression of its target genes in different organs[20],[21]. This organ-autonomous nature of TH-regulation has made it possible to reproduce the metamorphic transformations in organ cultures, thus providing an opportunity for relatively straightforward functional studies of extracellular proteins such as MMPs in vitro.

The involvement of MMPs in anuran development was first revealed more than 30 year ago when Gross and colleagues first discovered collagenase activities in the resorbing tail during metamorphosis[22]. More recently, several MMP genes were found to be among the TH-induced genes in various organs during metamorphosis[23-26].

To investigate the possible roles of MMPs during Xenopus development, we have now analyzed in detail the spatial temporal expression profiles of three MMPs, stromelysin-3 (ST3), collagenase-3 (Col3), and Col4, during development. For this purpose, we focus on intestinal remodeling and tail resorption. Although these two processes occur at different developmental stages, both take place when plasma TH levels are high (Fig 1). Furthermore, both involve extensive apoptosis. In the intestine, the larval epithelial cells undergo apoptosis, and in the tail, all cells eventually die. On the other hand, the two organs consist of very different cell types with different extracellular matrices, suggesting possible differential requirements for MMPs. Indeed, our results suggest that different MMPs play different roles in regulating cell death and tissue morphogenesis during metamorphosis.

\section{MATERIALS AND METHODS}

\section{In situ hybridization of tissue sections}

Tail and anterior small intestine from tadpoles at indicated stages were washed with PBS and fixed for $2 \mathrm{~h}$ in PBS containing 4\% paraformaldehyde. Following 3-4 h of infusion in $0.5 \mathrm{M}$ sucrose in PBS, intestine fragments were embedded in OCT cryogenic embedding media (Miles Laboratories) and flash frozen in liquid nitrogen cooled isopentane. Cross-sections of $6 \mu \mathrm{m}$ thickness were cut and placed on Fisher Probe-On charged slides and air-dried overnight prior to use.

Tissue section slides were washed 3 times for 5 min in PBS $0.1 \%$ Tween-20. Tissues were then permeabilized with $20 \mu \mathrm{g} / \mathrm{ml}$ proteinase $\mathrm{K}$ for $3 \mathrm{~min}$ at room temperature followed by refixation in $4 \%$ paraformaldehyde in PBS for $10 \mathrm{~min}$ and then washed several times with PBS $0.1 \%$ Tween-20. Samples were acetylated with a 10-min treatment in $0.1 M$ triethanolamine $\mathrm{pH} 8.0$ with 
MMPs in Xenopus laevis development

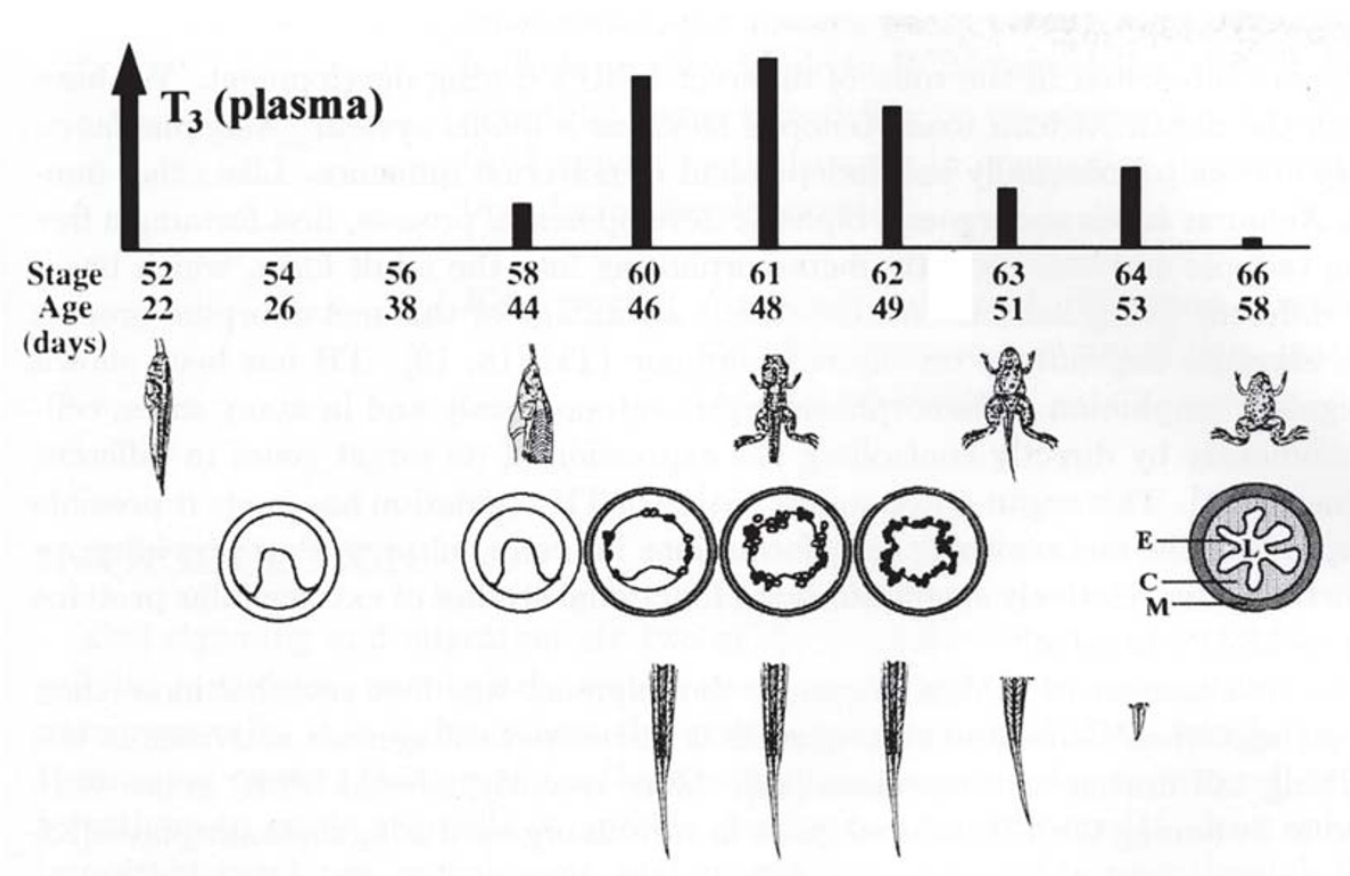

Fig 1.

Correlation of intestinal remodeling and tail resorption with plasma thyroid hormone concentration. The plasma T3 levels are from[45] and the developmental stages are based on[46]. Intestinal remodeling begins around stage 58 when the connective tissue increases in thickness. By stage 60 , adult epithelial cells can be detected as proliferating cell islets (dots) and larval epithelial cells begin to die through apoptosis (open circles). By stage 62, larval epithelial cell death is essentially complete and adult epithelial cells begin to differentiate to form the multiply folded adult epithelium. The connective tissue and muscles of the intestine develop extensively as well. Tail resorption as measured by tail length reduction begins around stage 62 and completes with 10 days. C, connective tissue; $\mathrm{M}$, muscles; E, epithelium; L, intestinal lumen.

$0.25 \%$ acetic anhydride. Following several washes in PBS $0.1 \%$ Tween-20, slides were prehybridized in $50 \%$ formamide and $5 \times \mathrm{SSC}$ for $30 \mathrm{~min}$ at $67{ }^{\circ} \mathrm{C}$. Hybridization solution consisted of $50 \%$ formamide, $5 \times \mathrm{SSC}, 1 \times$ Denhart's, $100 \mu \mathrm{g} / \mathrm{ml}$ sheared salmon sperm DNA and $100 \mu \mathrm{g} / \mathrm{ml}$ yeast tRNA and 300-500 ng/ml Digoxigenin (DIG)-labeled RNA probe. Hybridization was at $67{ }^{\circ} \mathrm{C}$ overnight. A 5 -min wash in $2 \times \mathrm{SSC}$ at $67{ }^{\circ} \mathrm{C}$ was then followed by $2 \times 30$-min washes in $0.2 \times$ $\mathrm{SSC}$ at $72{ }^{\circ} \mathrm{C}$. Slides were then rinsed with $0.2 \times \mathrm{SSC}$ at room temperature and washed twice for 5 min in $100 \mathrm{mM}$ Tris pH 7.4, $150 \mathrm{mM} \mathrm{NaCl}$. Samples were blocked for $1 \mathrm{~h}$ in $100 \mathrm{mM}$ Tris pH 7 . 4, $150 \mathrm{mM} \mathrm{NaCl}$ containing 10\% sheep serum and a 1:2000 dilution of an alkaline phosphataseconjugated DIG antibody was added and incubated overnight at $4{ }^{\circ} \mathrm{C}$. Four 5 -min washes were followed by one 15 -minute wash, and the colorimetric reaction was then developed.

TUNEL assays of apoptotic cells 
TUNEL (terminal deoxyribonucleotidyl transferase-mediated dUTP-biotin nick end labeling) assays on tissue sections were performed using Promegas DEADEND TUNEL kit (G7130) per instructions of the manufacturer. Briefly, $4 \%$ paraformaldehyde fixed sections were embedded in OCT cryosectioning media (Miles laboratories) and $6 \mathrm{~mm}$ sections were taken. Following brief post fixation in $4 \%$ paraformaldehyde, proteinase $\mathrm{K}$ treatment, $4 \%$ paraformaldehyde again, and PBS washes, samples were incubated with biotinylated nucleotide and terminal transferase at 37 ${ }^{\circ} \mathrm{C}$ for 30 min. Following washes and quenching of endogenous peroxidase activity using $\mathrm{H}_{2} \mathrm{O}_{2}$, the biotin label was detected with streptavidin-HRP (horse radish peroxidase) and a DAB (diaminobenzidine tetrahydrochloride dihydrate) color reaction.

\section{RESULTS}

The three MMP genes, ST3, Col3 and Col4, are all upregulated by TH during Xenopus laevis metamorphosis. However, they have different expression profiles. Northern blot analyses have shown that while Col3 and Col4 are dramatically activated during tail resorption, they are expressed at much lower levels in the metamorphosing intestine [23],[25],[26]. ST3 is, however, highly expressed in both organs during metamorphosis. Another important difference between ST3 and the collagenase genes is the kinetics of their upregulation during treatment of premetamorphic tadpoles with physiological concentrations of TH. ST3 is induced in both the intestine and tail within a few hours of TH treatment while Col3 and Col4 are significantly upregulated only in the tail and only after extended TH treatment $\geqslant 1$ day) $[25,26]$. These differences prompted us to compare the spatial temporal expression profiles of these MMPs and their relationship with tissue transformations in these two organs.

\section{ST3 but not Col3 or Col4 is associated with apoptosis during intesti- nal metamorphosis}

In situ hybridization was carried out to determine the spatial expression of the MMPs during metamorphosis. In the intestine, there was no detectable ST3 mRNA prior to stage 56, in agreement with our earlier studies (Fig 2B)[25]. Starting at stage 58, ST3 expression was greatly upregulated only in the connective tissue and by stage 60 , ST3 mRNA was present at high levels in nearly all connective tissue underlying the larval epithelium (Fig 2E). Subsequently, after stage 62, the ST3 mRNA could no longer be detected (data not shown), as expected from Northern blot studies[25].

A major event during intestinal remodeling is the degeneration of larval epithelium (Fig 1). To determine if ST3 expression may play a role in larval epithelial degeneration, apoptosis was analyzed by using the in situ TUNEL method on serial sections of the same intestinal fragments used for in situ hybridization analysis of ST3 expression. In premetamorphic tadpole intestine, when ST3 mRNA was not expressed (Fig 2B), no cell death could be detected by TUNEL labeling (Fig 2C). On the other hand, at stage 60/ 61, when ST3 was highly expressed in the intestinal connective tissue, apoptosis could be detected in the larval epithelium but rarely in other tissues (Fig 2F). After stage 62, as ST3 expression was suppressed, apoptosis could no longer be observed (data not 
MMPs in Xenopus laevis development

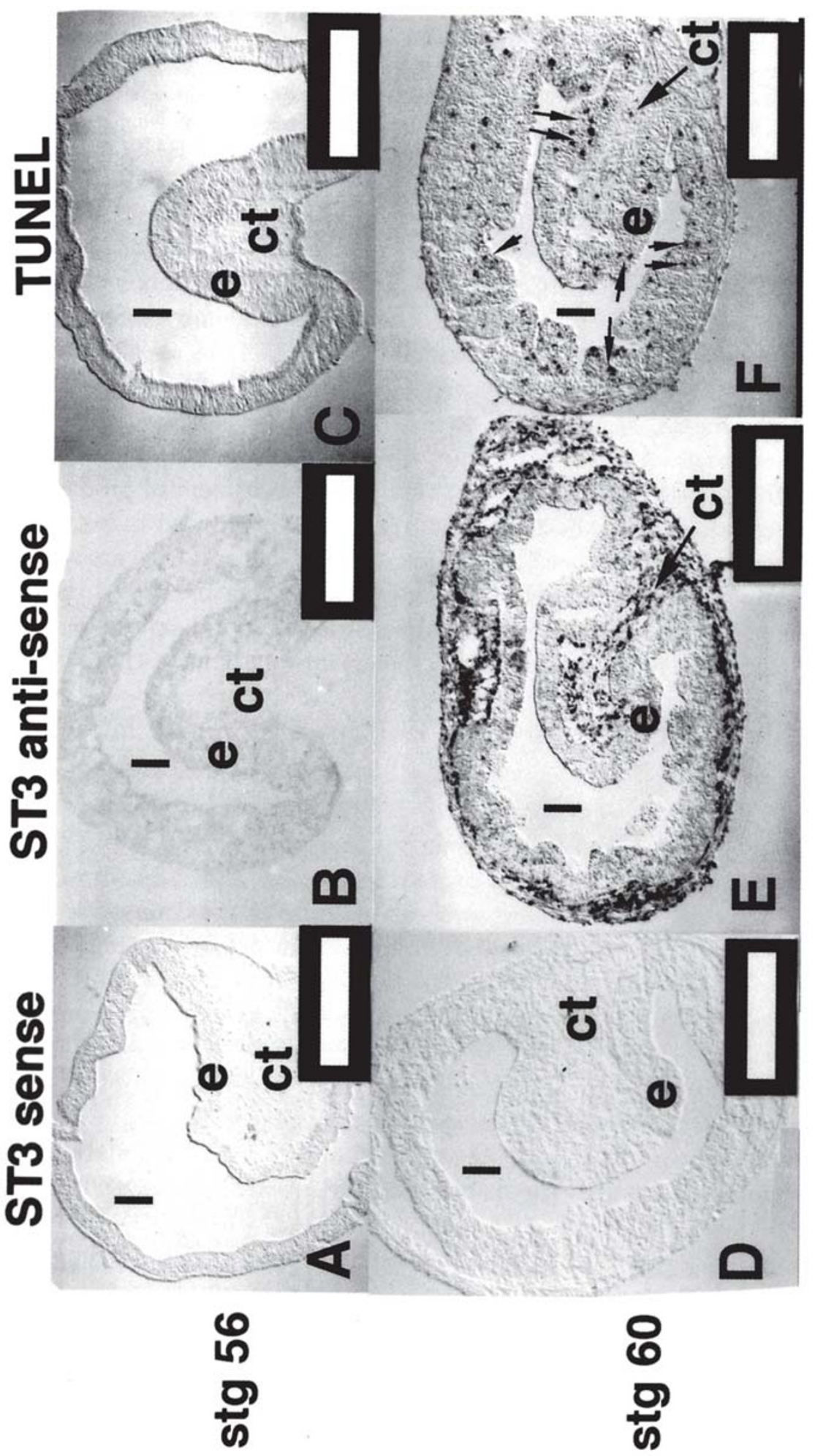




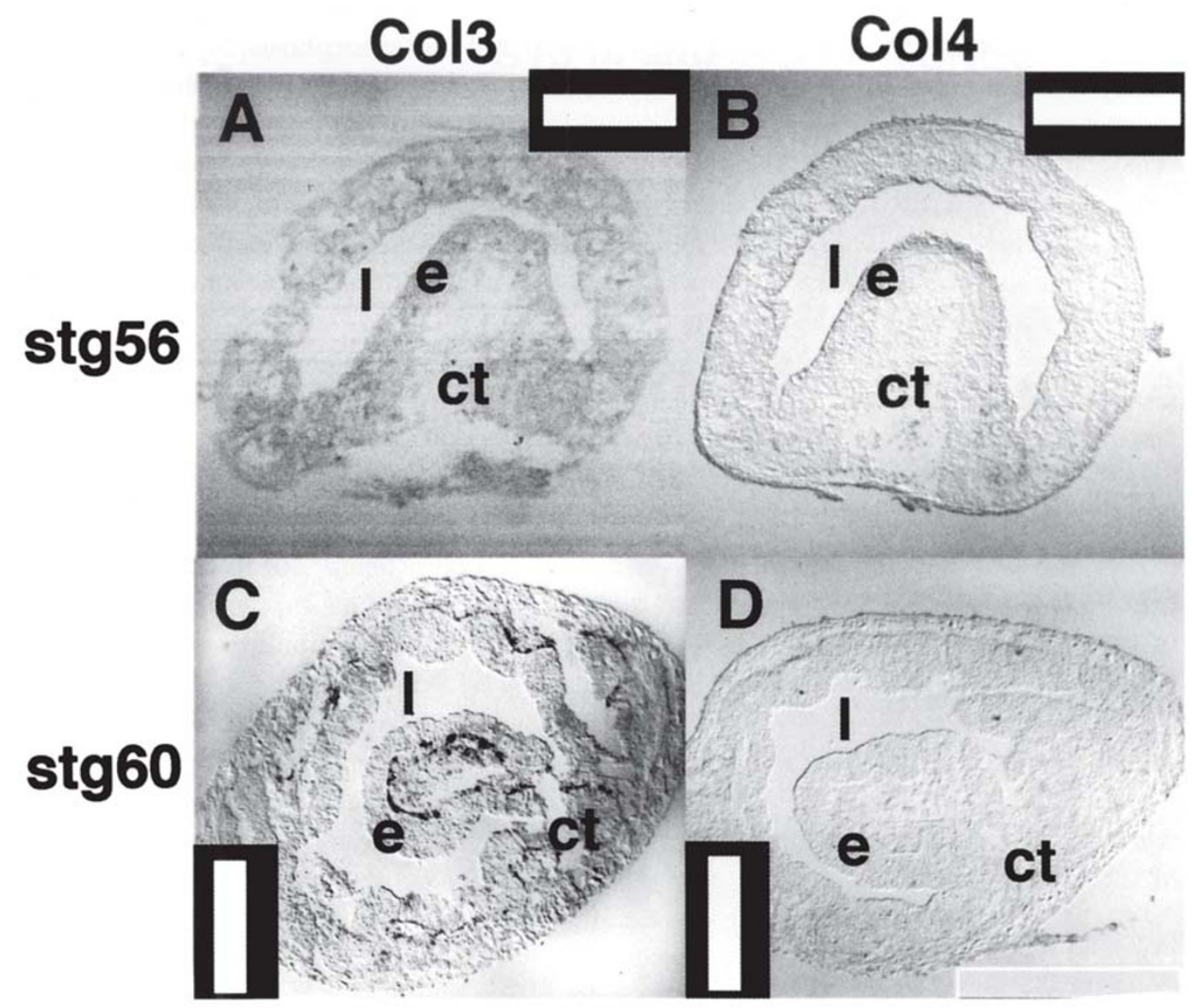

Fig 3.

Collagenase-3, but not collagenase-4, can be detected by in situ hybridization during intestine metamorphosis. In situ hybridization for collagenase-3 $(\mathrm{A}, \mathrm{C})$ and collagenase-4 (B, D) at stage $56(\mathrm{~A}, \mathrm{~B})$ and stage 60 (C, D) demonstrated that collagenase- 3 was expressed only at stage 60 and only in a subset of the connective tissue cells. ct, connective tissue; e, epithelium; l, lumen. White bars: $250 \mu \mathrm{m}$.

\section{$\triangleleft \quad$ Fig 2.}

Association of ST3 expression with larval epithelial cell death during intestinal remodeling. Stages 56 (A, B, C) and stage 60 (D, E, F) intestines were analyzed by in situ hybridization for ST3 expression (A, B, D, E) and by TUNEL assays for apoptotic cell detection (C, F). There was no detectable ST3 expression at stage 56 (B). ST3 expression was strong in all regions of the connective tissue at stage 60 but not in the epithelium or muscles (E). Likewise, at stage 56, there was no apoptotic signals (C), while there was many apoptotic signals, mainly within the epithelium, at stage 60 (arrows). Note that the control hybridization with the sense RNA probe did not detect any signal, as expected. ct, connective tissue; e, epithelium; l, lumen. White bars: $250 \mu \mathrm{m}$. 
MMPs in Xenopus laevis development

shown).

Unlike ST3, both Col3 and Col4 are expressed only weakly in premetamorphic intestine and slightly upregulated during intestinal metamorphosis[26]. In situ hybridization detected little or no Col4 expression in either premetamorphic or metamorphosing intestine under our conditions (Fig 3 B and D), possibly due to lower sensitivity of the assay. On the other hand, in situ hybridization revealed sporadic regions of $\mathrm{Col} 3 \mathrm{ex}-$ pression in the intestine at stage 60 (Fig 3C) but not in premetamorphic intestine (Fig 3A). Like ST3, Col3 mRNA was found exclusively in the connective tissue. However, no spatial correlation was found between Col3 expression and epithelial apoptosis (compare Fig $3 \mathrm{C}$ to $2 \mathrm{~F})$.

Correlation of ST3 and collagenase expression with apoptosis and connective tissue degradation, respectively, during tail resorption

In the tail, ST3 was detectable by in situ hybridization by stage 59 (data not shown), consistent with Northern blot analyses[23], [25]. By stage 62, strong ST3 expression was detected in most cells from the subepithelial fibroblasts to the fibroblasts in the notochordal sheath (Fig 4C, E). However, no expression was found in the muscles or epidermis (Fig 4C, E). ST3 mRNA level remained strong in the fibroblasts throughout tail resorption (e.g., stage 64, Fig 4G).

TUNEL labeling of apoptotic cells revealed that, by stage 62 , extensive cell death took place in the epidermis (Fig 4D, F) just above the subepithelial fibroblasts that expressed high levels of ST3. This apoptosis continued till the end of metamorphosis when all tail epidermis degenerated (e.g., Fig $4 \mathrm{H}$ for stage 64 when less than $10 \%$ of the tail remained).

Although there was overlap between regions of ST3 and Col3 expression within the intestine, Col3 was expressed predominantly in regions of the tail distinct to the regions expressing ST3. Like ST3, Col3 was expressed in the subepidermal fibroblasts at stages 59-61 (data not shown). However, its mRNA was barely detectable in this region by stages 62 to 64 (Fig 5A, C), when ST3 was highly expressed in this region and

\section{$\triangleright$ Fig 4.}

Stromelysin-3 expression in metamorphosing tail is also associated with apoptosis. Stage $62(\mathrm{~A}-\mathrm{F})$ and stage $64(\mathrm{G} . \mathrm{H})$ tail were analyzed by in situ hybridization for ST3 expression (A, C, E, G) and by TUNEL assays for apoptotic cells (B, D, F, H). There was no signal with the control sense cRNA probe on stage 62 tail (A) or with the TUNEL detection for cell death (B). There was strong ST3 expression at both stages $62(\mathrm{C}, \mathrm{E})$ and $64(\mathrm{G})$ in most connective tissue cells beneath the skin and around the muscles, but not in the notochord or its sheath. Concurrently, extensive apoptosis was detected in the tail, particularly within the epidermis (arrows in F, H) overlying the subepithelial fibroblasts expressing ST3. Panels (E) and (F) are higher magnifications of the tips of the tails shown in (C) and (D). n, notochord; ns, notochordal sheath; s, skin; sef, subepithelial fibroblasts. Bars in A, B, C, D: $100 \mu \mathrm{m}$; in $\mathrm{E}$ and $\mathrm{F}$ : $50 \mathrm{~mm}$; and in G, H: $200 \mu \mathrm{m}$. 
Damjanovski S, A Ishuzuya-Oka, YB Shi

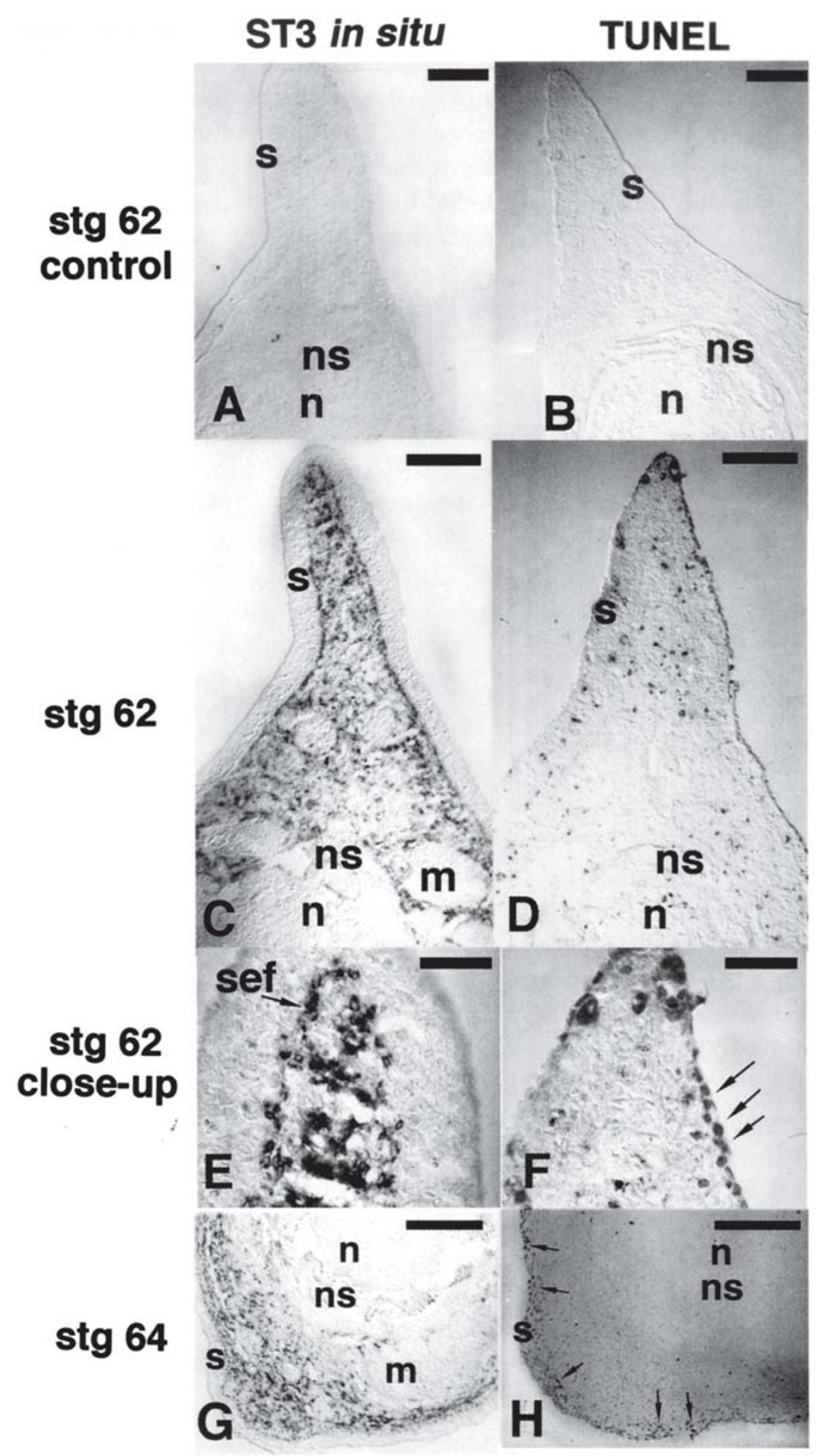


MMPs in Xenopus laevis development

epidermal apoptosis occurred (Fig 4D, F, H). On the other hand, Col3 was highly expressed in the cells surrounding the notochord at stages 62-64 (the notochordal sheath, Fig 5A, C) when rapid tail resorption took place, as reflected by the reduction in tail length. In contrast, ST3 had little expression in the notochordal sheath at these stages (Fig 4). Similar to Col3, Col4 was also expressed by cells within the notochordal sheath. Col4 expression, however, appeared to be restricted to the cells located closer to the notochord (Fig 5B, D). Furthermore, Col4 was not detected in the subepithelial fibroblasts at any of the analyzed stages (Fig 5B, D). In addition, as metamorphosis progressed, both Col3 and Col4 expression decreased as the notochord was resorbed, while ST3 mRNA remained very strong in the tail throughout all metamorphosing stages (Fig 4, 5, and data not shown).

\section{DISCUSSION}

Metamorphosis involves the transformation of essentially every tadpole organ/tissue. The tail and intestine represents two organs that are resorbed and remodeled, respectively. The analyses here demonstrate that these changes have distinct involvement of different MMPs. Our in situ hybridization data on ST3 in the intestine agrees with our earlier finding[27], and the data on ST3 and Col3 in the tail is consistent with the recent report by Berry et al.[28]. However, our detailed comparison of the three MMPs in the two organs and our analyses of the temporal regulation of cell death has not only extended these earlier studies but also revealed different roles of the MMPs during metamorphosis.

\section{The intestine}

The tadpole intestine consists predominantly of larval epithelial cells surrounded by thin layers of connective tissue and muscles. Its transformation to frog intestine involves the removal of larval epithelium through apoptosis followed by the development of the adult epithelium. Interestingly, extensive remodeling of the ECM separating the epithelium and connective tissue, i.e., the basal lamina or basement membrane, takes place during this transformation[29]. The basal lamina changes from a thin but continuous layer to a zig-zag, multiply folded, thick structure that appears to be more permeable to allow numerous cell-cell contacts and migration of macrophages into the degenerating epithelium[29],[30]. The activation of the ST3 gene in the fibroblasts underlying the epithelium coincides spatially and temporally with this ECM remodeling, immediately prior to larval cell death. ST3 expression persists throughout larval epithelial degeneration and adult epithelial cell proliferation (stage 59-62) and is downregulated as adult epithelial cell differentiation takes place after stage 62 . This expression profile suggests that, as an MMP, ST3 directly or indirectly modifies the basal lamina, thus altering cell-ECM and/or cell-cell interactions to facilitate larval epithelial cell death. Such a role for ST3 is similar to that implicated for stromelysin-1 during post-lactation mammary gland involution by expression studies as well as 
transgenic analyses[31-33]. It is also supported by in vitro studies of Xenopus larval intestinal epithelial cells, where the cells undergo TH-dependent apoptosis just like that in vivo and this cell death can be inhibited by coating the plastic dishes with ECM components[34].

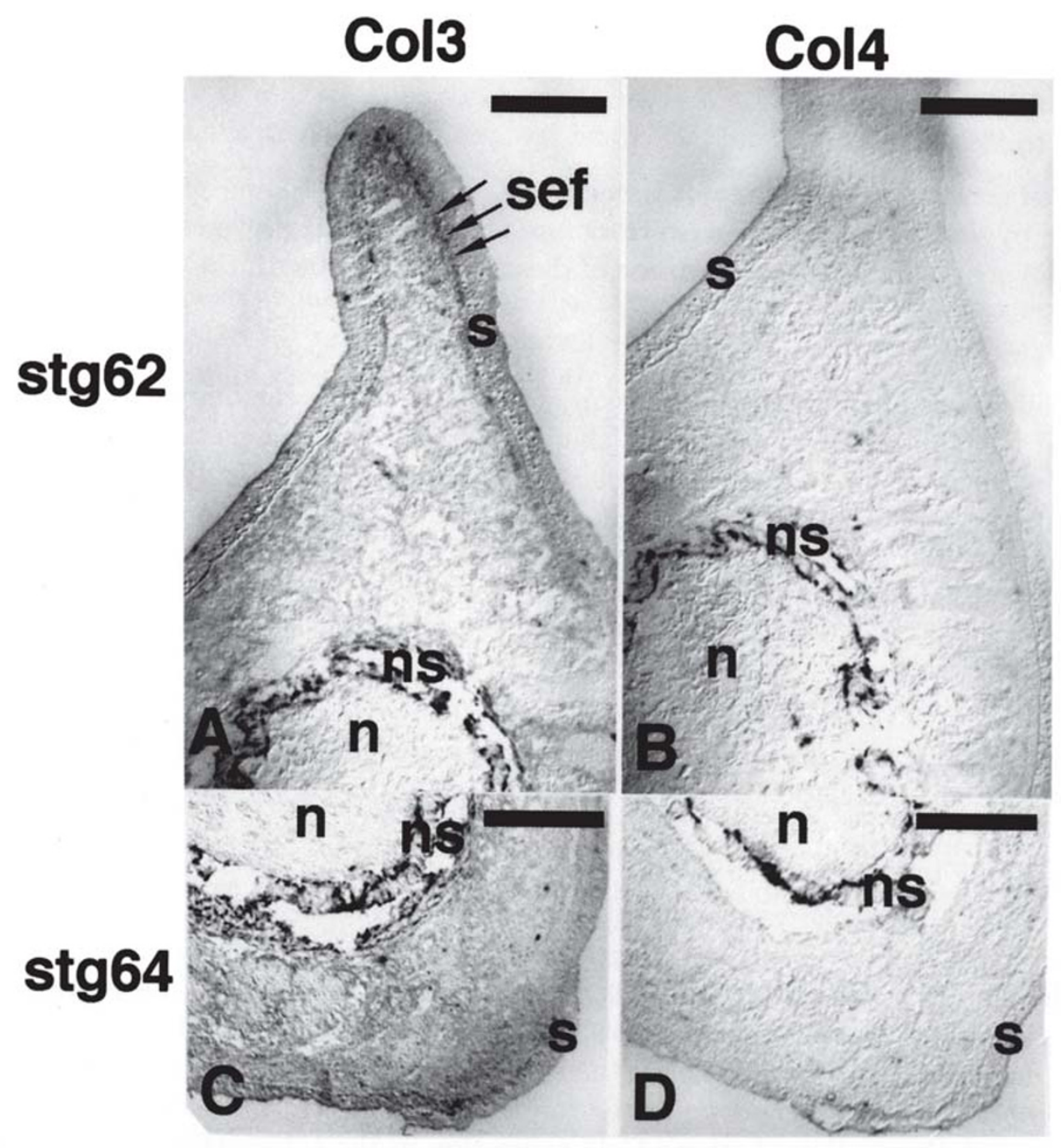

Fig 5.

Both collagenase- 3 and collagenase- 4 are abundantly expressed within the notochordal sheath during tail metamorphosis. In situ hybridization for collagenase-3 (A, C) and collagenase-4 (B, D) at stage $62(\mathrm{~A}, \mathrm{~B})$ and stage $64(\mathrm{C}, \mathrm{D})$ demonstrated that both mRNAs were detectable within the cells of the notochordal sheath through most of period of tail metamorphosis. Collagenase-3 was also detectable in the sub-epithelial fibroblasts at stage 62. n, notochord; ns, notochordal sheath; s, skin; sef, subepithelial fibroblasts. Bars in $\mathrm{A}, \mathrm{B}, 100 \mathrm{~mm}$; and in C, D: $200 \mu \mathrm{m}$. 


\section{MMPs in Xenopus laevis development}

Unlike ST3, Col3 and Col4 expression is only slightly elevated during intestinal metamorphosis[23],[26], which may be related to the fact that there is relatively little connective tissue in the tadpole intestine. Under our in situ hybridization conditions, Col4 expression was not detectable while Col3 was found to be expressed only in sporadic regions/cells within the connective tissue in the remodeling intestine. Thus, Col3 and Col4 may be involved in connective tissue remodeling to facilitate adult intestinal morphogenesis and possibly play a minor role in larval epithelial degeneration.

\section{The tail}

Tail consists of several major tissue types. These tissues are separated from each other by various ECMs. The expression of the three MMPs suggests that different MMPs are involved in the resorption of these different tissues during metamorphosis.

\section{The skin}

Tail skin is different from body skin in tadpoles. While the body skin undergoes larval to adult transformation, tail skin is eliminated during metamorphosis. The skin is made of an epidermis, which is separated from the dermis by a basement membrane. The tail skin degeneration appears to be dermis-dependent because, when tail skin is transplanted to body regions, its dermis is restructured and the skin survives metamorphosis to turn into adult skin; on the other hand, any skin placed on tail dermis degenerates[35]. As in the intestine, the basement membrane between the epidermis and dermis of the tail thickens during metamorphosis[36]. We and Berry et al.[28] have found that Col3 and ST3 are expressed by the sub-epithelial cells starting around stage 58 , coincident with these changes. In particularly, we have shown a tight correlation of ST3 expression with cell death not only in the skin but also in the muscles (see below). Thus, ST3 again appears to play a role in ECM remodeling to facilitate cell death.

We found no Col4 expression in the sub-epithelial cells. The Col3 expressed in these cells may play a role in collagen fiber fraying early during tail resorption[36]. Although Col3 may also facilitate epidermal cell death in the tail, its expression is not tightly associated with apoptosis. Compared to the notochord sheath cells, we saw decreased Col3 expression by the sub-epithelial cells after stage 62/63 despite the rapid cell death occurring in the tail skin (see Fig 2). This differs from Berry et al.'s[28] observation of strong Col3 expression in the sub-epithelial cells at stage 62/63. It is possible that such a difference is due to the analysis of different regions of the tail as there is a distal to proximal gradient of resorption with the distal end regressing faster[37]. As apoptosis was not analyzed in the study by Berry et al..[28], it is difficult to directly compare the two studies.

The notochord 
This is an important structural feature of the early embryos and is strongly reinforced by a sheath of collagen. The meshwork of collagen fibers which run circumferencially and longitudinally around the entire length of the notochord must be eliminated during tail resorption. Thus, not surprisingly, we found both Col3 and Col4 in the collagen-rich notochordal sheath. On the other hand, ST3 has little expression in this region. Throughout tail resorption, Col3 is expressed in the entire notochordal sheath, while Col4 expression is mainly restricted to the inner cells of the notochordal sheath. These observations are consistent with the studies on Col3 and ST3 by Berry et al.[28]. Thus, both collagenases are likely involved in collagen degradation to facilitate notochord removal while ST3 has little role in this mostly connective tissue-degradation event.

\section{The muscle}

This is the most abundant tissue of the tail. Muscle cell death also occurs through apoptosis[38-40] and appears to involve cell death regulators like caspases and Bax/ Bcl-2 family members[41],[42]. Both our study and Berry et al.' s[28] detected ST3 but not Col3 expression in the fibroblasts surrounding the muscle flank. In addition, we showed that Col4 is also absent in the muscle as well as the surrounding fibroblasts. Thus, like the epithelial cells in the tail and intestine, the muscle cell apoptosis is at least in part facilitated by remodeling of the surrounding ECM directly or indirectly mediated by ST3.

In conclusion, we have shown that ST3 appears to play a role in ECM remodeling that may facilitate cell death during metamorphosis. In contrast, the collagenases are involved mainly in connective tissue remodeling/degradation. Such a role for ST3 in cell death appears to be also conserved in mammals where ST3 is also highly expressed in tissues undergoing apoptotic remodeling such as during limb morphogenesis and mammary gland involution[42],[44], even though these processes are under different hormonal regulations. The future challenges will be to directly test the functions of these MMPs during tissue remodeling and determine the underlying molecular mechanisms.

\section{CKNOWLEDGEMENT}

We thank Ms. Kieu Pham for preparing the manuscript.

\section{REFERENCES}

[1] Hay ED. 'Cell Biology of Extracellular Matrix' 2nd ed. Plenum Press, New York. Hay, E.D. (1993) Extracellular matrix alters epithelial differentiation. Current Opinion in Cell Biol 1991; 5: 1029-35.

[2] Werb Z, Chin JR. Extracellular matrix remodeling during morphogenesis. Ann N Y Acad Sci 1998; 857:110-18.

[3] Alexander CM, Werb Z. Extracellular matrix degradation. In 'Cell Biology of Extracellular 


\section{MMPs in Xenopus laevis development}

Matrix', 2nd ed. (ed. E. D. Hay). Plenum Press, New York 1991; 255-302.

[4] Birkedal-Hansen H, Moore WGI, Bodden MK, Windsor LJ, Birkedal-Hansen B, DeCarlo A, Engler JA. Matrix metalloproteinases: a review. Crit Rev in Oral Biol and Med 1993; 4(2):197-250.

[5] Matrisian LM. The matrix-degrading metalloproteinases. Bioessays 1992; 14:455-63.

[6] Parks WC, Mecham RP. Matrix metalloproteinases. Academic Press, New York 1998.

[7] Pei D, Weiss SJ. Furin-dependent intracellular activation of the human stromelysin-3 zymogen. Nature 1995; 375:244-7.

[8] Uria JA, Werb Z. Matrix metalloproteinases and their expression in mammary gland. Cell Res 1998; 8:187-94.

[9] van Wart HE, Birkedal-Hansen H. The cysteine switch: A principle of metallo-proteinae activity with potential applicability to the entire matrix metalloproteinase gene family. Proc Natl Acad Sci USA 1990; 87:5578-82.

[10] Nagase J, Suzuki K, Morodomi T, Enghild JJ, Salvesen G. Activation Mechanisms of the Precursors of Matrix Metalloproteinases 1, 2, and 3. MATRIX Supple 1992; 1:237-44.

[11] Nagase H. Cell surface activation of progelatinase A (pro MMP-2) and cell migration Cell Res. 1998; 8:179-86.

[12] Kleiner Jr DE, Stetler-Stevenson WG. Structural biochemistry and activation of matrix metalloproteases. Current Opinion in Cell Biol 1993; 5:891-7.

[13] Murphy G, Willenbrock R, Crabbe T, O’ Shea M, Ward R, Atkinson S, O’ Connell J, Docherty A. Regulation of Matrix Metalloproteinase Activity. Annals of New York Academy of Sciences 1994; 732:31-41.

[14] Sang QA, Douglas DA. Computational sequence analysis of matrix metalloproteinases. J Protein Chem 1996; 15:137-60.

[15] Talhouk RS, Bissell MJ, Werb Z. Coordinated expression of extracellular matrix-degrading proteinases and their inhibitors regulates mammary epithelial function during involution. Journal of Cell Biol 1992; 118:1271-82.

[16] Stetler-Stevenson WG, Aznavoorian S, Liotta LA. Tumor cell interactions with the extracellular matrix during invasion and metastasis. Annu Rev Cell Biol 1993; 9:541-73.

[17] Tryggvason K, Hoyhtya M, Salo T. Proteolytic degradation of extracellular matrix in tumor invasion. Biochimica et Biophysica Acta 1987; 907:191-217.

[18] Dodd MHI, Dodd JM. The biology of metamorphosis. In physiology of the amphibia (ed. B. Lofts). Acadmic Press, New York 1976; pp.467-599.

[19] Gilbert LI, Frieden E. Metamorphosis: A problem in developmental biology, 2nd ed., Plenum Press, New York 1981.

[20] Galton VA. Thyroid hormone action in amphibian metamorphosis. In Oppenheimer, JH, Samuels, HH, eds. Molecular basis of thyroid hormone action. New York, Academic, 1983; pp 445-483

[21]orphosis: Post-embryonic reprogramming of gene expression in amphibian and insect cells. Academic Press, New York 1996.

[22] Gross J. How tadpoles lose their tails. The journal of investigative dermatology 1966; 47:274-7.

[23] Wang Z, Brown DD. Thyroid hormone-induced gene expression program for amphibian tail resorption. J Biol Chem 1993; 268:16270-8.

[24] Oofusa K, Yomori S, Yoshizato K. Regionally and hormonally regulated expression of genes of collagen and collagenase in the anuran larval skin. Int J Dev Biol 1994; 38:345-50.

[25] Patterton D, Hayes WP, Shi Y-B. Transcriptional activation of the matrix metalloproteinase gene stromelysin-3 coincides with thyroid hormone-induced cell death during frog metamorphosis. Dev Biol 1995; 167:252-62.

[26] Stolow MA, Bauzon DD, Li Jiwen, Sedgwick T, Liang VC-T, Sang QA, Shi Y-B. Identification and characterization of a novel collagenase in Xenopus laevis : Possible roles during frog development. Mol Biol of the Cell 1996; 7:1471-83. 


\section{Damjanovski S, A Ishuzuya-Oka, YB Shi}

[27] Ishizuya-Oka A, Ueda S, Shi Y-B. Transient expression of stromelysin-3 mRNA in the amphibian small intestine during metamorphosis. Cell Tissue Res 1996; 283:325-9.

[28] Berry DL, Schwartzman RA, Brown DD. The expression pattern of thyroid hormone response genes in the tadpole tail identifies multiple resorption programs. Develop Biol 1998a; 203:12-23

[29] Ishizuya-Oka A, Shimozawa A. Ultrastructural changes in the intestinal connective tissue of Xenopus laevis during metamorphosis. J Morphol 1987b; 193:13-22.

[30] Murata E, Merker HJ. Morphologic changes of the basal lamina in the small intestine of Xenopus laevis during metamorphosis. Acta Anat 1991; 140:60-9.

[31] Sympson CJ, Talhouk RS, Alexander CM, Chin JR, Clift SM, Bissell MM, Werb Z. Targeted Expression of Stromelysin-1 in Mammary Gland Provides Evidence for a Role of Proteinases in Branching Morphogenesis and the Requirement for an Intact Basement Membrane for Tissuespecific Gene Expression. J Cell Biol 1994; 125(3):681-93.

[32] Witty JP, Wright JH, Matrisian LM. Matrix metalloproteinases are expressed during ductal and alveolar mamary morphogenesis, and misregulation of stromelysin-1 in transgenic mice induces unscheduled alveolar development. Mol Biol Of the Cell 1995a; 6:1287-303.

[33] Witty JP, Lempka T, Coffey RJ Fr, Matrisain LM. Decreased tumor formation in 7, 12dimethylbenzanthracene-treated strmelysin-1 transgenic mice is associated with alternations in mammary epithelial cell apoptosis. Cancer Res 1995b; 55:1401-6.

[34] Su Y, Shi Y, Stolow MA, Shi Y-B. Thyroid hormone induces apoptosis in primary cell cultures of tadpole intestine: Cell type specificity and effects of extracellular matrix. J Cell Biol 1997; 139: 1533-43.

[35] Kinoshita T, Sasaki F, Watanabe K. Regional specificity of anuran larval skin during metamorphosis: dermal specificity in development and histolysis of recombined skin grafts. Cell Tissue Res 1986; 245:297-304.

[36] Usuku G, Gross J. Morphologic studies of connective tissue resorption in the tail fin of metamorphosing bullfrog tadpole. Develop Biol 1965; 11:352-70.

[37] Dymtrenko GM, Kirby GS. Tail regression during amphibian metamorphosis. J Exp Zool 1981; 215:179-82.

[38] Watanabe K, F Sasaki. Ultrastructural changes in the tail muscles of anuran tadpoles during metamorphosis. Cell Tissue Res 1974; 155:321-36.

[39] Kerr JF, Harmon B, Searle J. An electron-microscope study of cell deletion in the anuran tadpole tail during spontaneous metamorphosis with special reference to apoptosis of striated muscle fibers. J Cell Sci 1974; 14:571-85.

[40] Nishikawa A, Hayashi H. Spatial, temporal and hormonal regulation of programmed muscle cell death during metamorphosis of the frog Xenopus laevis Differentiation 1995; 59:207-14.

[41] Sachs LM, Abdallah B, Hassan A, Levi G, De Luze A, Reed JC, Demeneix BA. Apoptosis in Xenopus tadpole tail muscles involves Bax-dependent pathways. The FASEB J 1997; 11:801-8.

[42] Yaoita Y, Nakajima K. Induction of apoptosis and CPP32 expression by thyroid hormone in a myoblastic cell line dervied from tadpole tail. J Biol Chem 1997; 272:5122-7.

[43] Basset P, Bellocq JP, Wolf C, Stoll I, Hutin P, Limacher JM, Podhajcer OL, Chenard MP, Rio MC, Chambon P. A novel metalloproteinase gene specifically expressed in stromal cells of breast carcinomas. Nature 1990; 348:699-704.

[44] Lefebvre O, Wolf C, Limacher JM, Hutin P, Wendling C, LeMeur M, Basset P, Rio M-C. The breast cancer-associated stromelysin-3 gene is expressed during mouse mammary gland apoptosis. $\mathrm{J}$ of Cell Biol 1992; 119:997-1002.

[45] Leloup J, Buscaglia M. La triiodothyronine: hormone de la m?amorphose des amphibiens. CR Acad Sci 1977; 284:2261-3.

[46] Nieuwkoop PD, Faber J. Normal table of Xenopus laevis. North Holland Publishing, Amsterdam 1956.

Received April-28-1999. Revised May-11-1999. $\quad$ Accepted May-17-1999. 